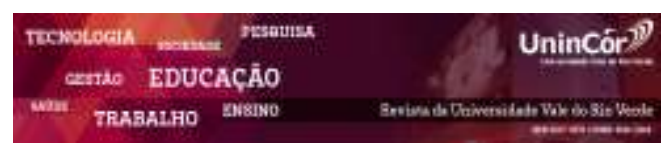

Revista da Universidade Vale do Rio Verde ISSN: 1517-0276 / EISSN: 2236-5362 Vol. 16 | n. 1 | Ano 2018

Alison Geovani Schwingel Franck Universidade Federal de Santa Maria (UFSM) alischfranck@hotmail.com

Laís Viera Trevisan

Universidade Federal de Santa Maria (UFSM) laisvtrevisan@gmail.com

Giulia Xisto de Oliveira Universidade Federal de Santa Maria (UFSM) giuliaxisto@gmail.com

Rodrigo Abbade da Silva Universidade Federal de Santa Catarina (UFSC) abbaders@gmail.com

Daniel Arruda Coronel Universidade Federal de Santa Maria (UFSM) daniel.coronel@uol.com.br

\section{ANÁLISE EMPÍRICA DO PADRÃO DE ESPECIALIZAÇÃO DO COMÉRCIO INTERNACIONAL DO ESTADO DO PARÁ (1999-2016) ${ }^{1}$}

\section{RESUMO}

Este trabalho buscou analisar o padrão de especialização do comércio internacional do estado do Pará, identificando os setores produtivos mais dinâmicos, no período entre 1999 e 2016. Para isso, foram calculados os indicadores de Vantagem Comparativa Revelada Simétrica (IVCRS), de Comércio Intraindústria (CII), de Concentração Setorial das Exportações (ICS) e Taxa de Cobertura das Importações (TC) com os dados obtidos da Secretaria de Comércio Exterior - SECEX. Os resultados apontam que o Pará possui uma pauta de exportações pouco diversificada. Os resultados do IVCRS indicam que o setor de minerais, de madeira, de químicos e de metais comuns são os setores que apresentaram vantagens comparativas. Quanto aos resultados do CII, observa-se que o estado do Pará ainda não teve significativo impacto na integração regional por meio do aproveitamento do comércio intraindustrial. Além destes indicadores, o ICS revela que a pauta exportadora do estado é concentrada, e ainda, a TC aponta que os setores de madeira, minerais, calçados e couro, papel e metais comuns foram os que tiveram suas importações cobertas pelas respectivas exportações.

Palavras-chave: Exportações. Vantagem comparativa. Pará.

\begin{abstract}
This study aimed to analyze the specialization pattern of international trade in the state of Pará, identifying the most dynamic productive sectors in the period between 1999 and 2016. In this sense, the Revealed Symmetric Comparative Advantage indicator (RSCA) was calculated, as well as the Intra-Industry Trade index (IIT), the Industry Concentration of Exports (ICS) and the Import Coverage Ratio (ICR), based on data obtained from the Foreign Trade Office (SECEX). The results indicated that the state of Pará has a very diversified export basket. The results of the RSCA indicated that the sector of minerals, wood, chemicals and basic metals presented comparative advantages.
\end{abstract}

${ }^{1}$ Este trabalho teve o aporte financeiro do Conselho Nacional de Desenvolvimento Científico e Tecnológico (CNPq), sendo que o projeto visa identificar o padrão de especialização comercial dos vinte e seis estados da federação e mais o Distrito Federal. 
Regarding the results of the IIT, it was observed that the state of Pará has not yet had a significant impact on regional integration through the use of intra-industry trade. In addition to these indicators, the ICS showed that the state's export basket is concentrated, and the ICR pointed out that the sectors of wood, minerals, footwear and leather, paper and basic metals had their imports covered by the respective exports.

Keywords: Exports. Comparative advantage. Pará.

\section{Recebido em: 10/01/2018 - Aprovado em: 01/06/2018 - Disponibilizado em: 15/07/2018}

\section{INTRODUÇÃO}

O comércio internacional tem experimentado grandes crescimentos, sobretudo nas últimas três décadas. Além do crescimento, observa-se que há profundas transformações em suas estruturas através de novas formas de organização e coordenação da produção industrial. Antes, a cadeia produtiva de bens se concentrava basicamente em um determinado país e era até mesmo dependente de uma única empresa, mas hoje pode-se perceber uma melhor distribuição geográfica e fragmentada, criando cadeias globais de valor (OLIVEIRA, 2014).

Os estudos acerca da temática tiveram início há três séculos com Adam Smith e David Ricardo. O primeiro formulou a teoria das vantagens absolutas e o segundo a das vantagens comparativas. Para Smith, a produção que necessita de uma quantidade menor de insumos é a que possui uma vantagem absoluta, já, para Ricardo, a vantagem comparativa é usada para medir o custo de oportunidade. Ao abrir mão de produzir vários produtos e focar em apenas um bem específico, a produção terá menor custo de oportunidade e, portanto, uma vantagem comparativa nas suas operações (SOARES; SILVA, 2013).
Para Ferreira et al. (2010), o fluxo do comércio internacional ocorre em diferentes níveis devido às diferentes formas de produção e trabalho de cada país, por isso, Eli Heckscher (1919) e Bertil Ohlin (1933) buscaram compreender as causas desses diferentes padrões em cada país com a identificação dos fatores responsáveis por essa diferença. Eles afirmam que um país terá uma vantagem comparativa em sua produção quando houver abundância relativa dos fatores de produção, além de intensidade na alocação desses fatores dentro do processo produtivo.

Diante desse contexto, destaca-se a relevância de se estudar a pauta exportadora dos estados brasileiros e, neste artigo, especificamente, o padrão do comércio internacional do estado do Pará. A importância do estudo se dá devido à grande participação desse estado nas exportações do Brasil, ocupando o $7^{\circ}$ lugar no ranking em 2017, atingindo um valor de US\$ $14.484,46$ nesse ano. Os principais produtos exportados são minérios de ferro, minérios de cobre e óxidos e hidróxidos de alumínio e alguns dos principais destinos são China, Alemanha e Noruega (MINISTÉRIO DO DESENVOLVIMENTO, INDÚSTRIA E COMÉRCIO EXTERIOR - MDIC, 2017a). 
Segundo o Instituto Brasileiro de Estatística e Geografia (IBGE, 2017), o Pará possui uma área de 1.247.955,238 km² e uma população estimada, para 2017 , de 8.366 .628 habitantes. O estado conta com 144 municípios, sendo Belém a capital. No estado, há 2.238 indústrias locais que empregam a 104.662 pessoas.

O presente trabalho está estruturado em cinco seções, sendo a primeira essa introdução; a segunda traça um panorama das exportações do Pará; na terceira seção, apresenta-se a metodologia utilizada; na quarta, descrevem-se os resultados encontrados e, por fim, na quinta, apresentam-se as conclusões.

\section{A ESTRUTURA DAS EXPORTAÇÕES DO PARÁ}

De acordo com o MDIC (2017a), em 2016, as exportações do Pará totalizaram US\$ 10.511.327.726 milhões, ocupando a $7^{\mathrm{a}}$ posição no ranking dos estados brasileiros, com uma participação de $81,56 \%$ nas exportações da
Região Nordeste e 5,85\% nas da nação. Em 1999, o Pará exportava US\$ 2.135.959.720 milhões, também em $7^{\mathrm{a}}$ posição nacional e possuía $79,78 \%$ de participação nas exportações da Região Norte e 4,56\% nas do Brasil. De 1999 a 2016, as exportações do Pará cresceram 392\%, enquanto as do Brasil, 284\%.

Já em relação às importações, o valor total, em 2016, para o estado do Pará, foi de US\$ 1.104.081.440 milhões, ocupando a $17^{\mathrm{a}}$ posição nacional, com uma participação de $13,72 \%$ nas importações da Região Norte e de 0,80\% nas do país. Em 1999, o valor era de US\$ 170.846 .778 milhões, e o estado figurava na $15^{\mathrm{a}}$ posição, com 0,35\% de participação nas exportações do Brasil e 5,51\% nas da Região Norte. Assim, de 1999 a 2016, as importações do estado cresceram $546 \%$ e as do Brasil, $179 \%$.

Com base nesses dados, verifica-se que, de 1999 a 2016, tanto as exportações quanto as importações do Pará cresceram mais que as do país.

A Figura 1 apresenta as exportações do Pará segundo o fator agregado.

Figura 1 - Exportações (X) do Pará segundo fator agregado (em milhões US\$ FOB)

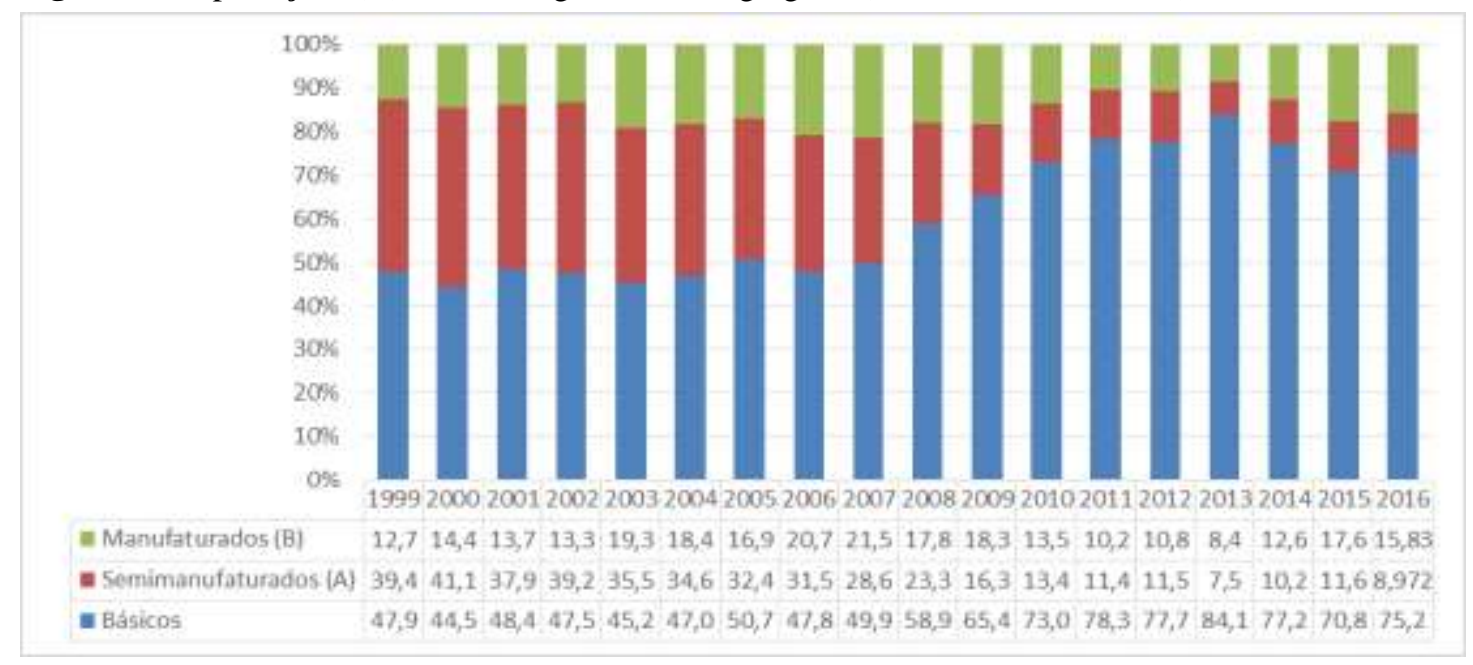


Fonte: Elaboração própria a partir dos dados MDIC/SECEX (2017b).

Conforme a Figura 1, observa-se que, ao longo do período analisado, os produtos básicos foram aumentando significativamente sua participação nas exportações, passando de 47,9\% em 1999 para 75,2\% em 2016, enquanto os semimanufaturados reduziram de 39,4\% em 1999 para $8,97 \%$ em 2016. Já os produtos manufaturados apresentaram um pequeno aumento.
De acordo com o MDIC (2017a), o principal produto exportado pelo Pará, em 2016, foi "minérios de ferro não aglomerados e seus concentrados", com 45,55\% de participação nas exportações. $\mathrm{O}$ segundo produto mais exportado foi "outros minérios de cobre e seus concentrados" $(13,99 \%)$.

A Figura 2 apresenta as importações do Pará segundo o fator agregado.

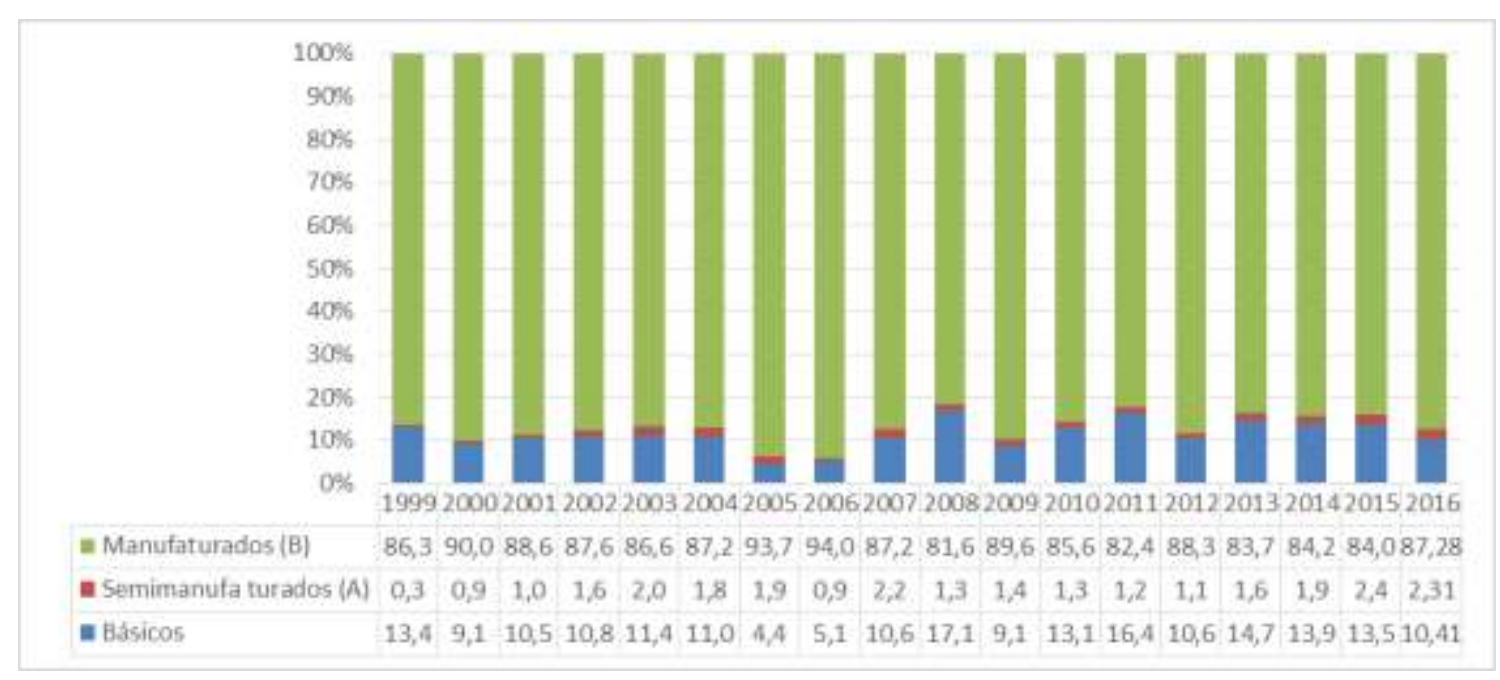

Figura 2 Importaçõe $\mathrm{s}(\mathrm{M}) \mathrm{do}$

Pará segundo fator agregado (em milhões US\$ FOB)

Fonte: Elaboração própria a partir dos dados MDIC/SECEX (2017b)

A estrutura das importações do Pará não teve grandes modificações ao longo do período de análise. Os produtos manufaturados respondem pela maior parcela das importações, chegando à participação de $87,28 \%$ em 2016, enquanto os básicos passaram de 13,4\% em 1999 para 10,41\% em 2016. Os semimanufaturados aumentaram poucos pontos percentuais no período.
Segundo o MDIC (2017a), em 2016, o principal produto importado pelo estado foi "hidróxido de sódio em solução aquosa", com $13,92 \%$ de representação. O segundo produto foi "outras máquinas e aparelhos para esmagar", com 10,87\% de participação.

Considerando a relevância das exportações no papel de especialização comercial, 
Tabela 1 - Destino das exportações e sua participação no total exportado pelo PA - 1999 e 2016

\begin{tabular}{|c|c|c|c|c|c|c|c|}
\hline Posição & Países de destino & $\begin{array}{c}\text { Exp. em } 2016 \\
\text { (milhões US\$ } \\
\text { FOB) }\end{array}$ & $\begin{array}{c}\text { Part. \% } \\
\text { em } 2016\end{array}$ & Posição & Países de destino & $\begin{array}{l}\text { Exp. em } 1999 \\
\text { (milhões US\$ } \\
\text { FOB) }\end{array}$ & $\begin{array}{l}\text { Part. \% } \\
\text { em } 1999\end{array}$ \\
\hline $1^{\circ}$ & China & 3526,2 & 33,5 & $1^{\circ}$ & Japão & 533,2 & 25,0 \\
\hline $2^{\circ}$ & Japão & 693,0 & 6,6 & $2^{\circ}$ & Estados Unidos & 308,1 & 14,4 \\
\hline $3^{\circ}$ & Alemanha & 534,0 & 5,1 & $3^{\circ}$ & Bélgica - Luxemburgo & 183,8 & 8,6 \\
\hline $8^{\circ}$ & Estados Unidos & 385,7 & 3,7 & $4^{\circ}$ & Alemanha & 137,8 & 6,5 \\
\hline \multirow[t]{3}{*}{$<30^{\circ}$} & $\begin{array}{c}\text { Bélgica - } \\
\text { Luxemburgo }\end{array}$ & 38,5 & 0,4 & $13^{\circ}$ & China & 51,5 & 2,4 \\
\hline & Demais Países & 5333,9 & 50,7 & & Demais Países & 921,4 & 43,1 \\
\hline & Total & 10511,3 & 100,0 & & Total & 2135,9 & 100,0 \\
\hline
\end{tabular}

Fonte: Elaboração própria a partir dos dados MDIC/SECEX (2017b).

De acordo com a Tabela 1, verificam-se mudanças nos destinos das exportações do Pará. Em 1999, o Japão ocupava a primeira posição no ranking, detendo $25 \%$ das exportações do estado, seguido pelos Estados Unidos, com 14,4\%, Bélgica com 8,6\% e Alemanha, com 6,5\%. Assim, os quatro países juntos representavam $56,9 \%$ do total exportado pelo Pará.

Já em 2016, o Japão diminuiu sua participação para $6,6 \%$ e passou para o segundo lugar, cedendo o primeiro lugar para a China, que, em 1999, estava em $13^{\text {a }}$ colocada, com $2,4 \%$ de representação, passando para 33,5\% em 2016. Os Estados Unidos, que estavam em segundo lugar, passaram para $8^{\circ}$, diminuindo para $3,7 \%$ de participação. A Bélgica foi da terceira posição para abaixo da $30^{\mathrm{a}}$, diminuindo para $0,4 \%$ sua representação. Por fim, a Alemanha, que estava em quarto, passou para a terceira posição $(5,1 \%)$. Os três principais destinos do Pará, em 2016, juntos, representam $45,2 \%$ do total exportado.
Isso mostra uma pequena diminuição da concentração se comparado ao ano de 1999.

O estado do Pará é reconhecido pelo setor de minérios, e a maior parte dos minérios extraídos do seu território tem como destino os Estados Unidos da América, China, Japão, Alemanha e dentre outros. Ainda não se estudam formas de utilizar esses produtos no próprio estado, exceto no caso da bauxita, que é transportada ao complexo Alunorte-Albrás, localizada no município de Barcarena, onde é utilizada para a produção do alumínio (TOBIAS; COSTA; BAHIA, 2014).

Conforme Lima e Silva (2016), desde 1967 tem sido observada uma maior abertura da mineração paraense ao capital estrangeiro, possibilitando novas dinâmicas, descobertas e fomento. A partir de 1980, as empresas começaram a competir pelo potencial mineral do estado e, desde então, suas fronteiras têm-se expandido em escala global. Em 2013, as indústrias de mineração e de transformação 
mineral foram responsáveis por $88 \%$ das exportações do estado. Além disso, a indústria mineral do Pará pretende investir, até 2018, quase US\$ 34 bilhões em extração de minerais, mais de US\$ 7 bilhões em infraestrutura e transporte, US\$ 4,5 bilhões em transformação mineral e US\$ 1,5 bilhões em outros negócios. Para Jerônimo e Sonaglio (2014), o estado acumulou US\$ 104.4 bilhões entre 1997 a 2012 nas exportações, sendo os minérios responsáveis por $54 \%$ desse valor, seguidos pelo alumínio $(11,25 \%)$ e madeira $(6,49 \%)$.

No que tange à estrutura das exportações do Pará segundo os grupos de produtos (Tabela 2), os setores que apresentaram as maiores taxas de crescimento das exportações, entre os anos 1999 e 2016, foram minerais $(908,05 \%)$, metais comuns $(481,03 \%)$ e madeira $(277,63 \%)$. 
Tabela 2 - Estrutura das exportações do Pará segundo grupos de produtos/setores em (\%)

\begin{tabular}{|c|c|c|c|c|c|c|c|c|c|c|c|c|c|c|c|c|c|c|c|}
\hline Setores\períodos & 1999 & 2000 & 2001 & 2002 & 2003 & 2004 & 2005 & 2006 & 2007 & 2008 & 2009 & 2010 & 2011 & 2012 & 2013 & 2014 & 2015 & 2016 & $\begin{array}{c}\text { Taxa } \\
\text { de cresc. } \\
1999 \text { a } \\
2016\end{array}$ \\
\hline Alimentos/fumo/ & & 127,2 & 111,8 & 104,6 & 132,5 & 142,0 & 184,0 & 270,2 & & & & 1.030 & & 1.216 & 1.506 & & & & \\
\hline bebidas & 137,22 & 7 & 0 & 9 & 1 & 3 & 6 & 6 & 485,77 & 648,27 & 723,92 & 43 & $1.043,79$ & 65 & 0 & $1.637,71$ & $1.192,28$ & $1.031,48$ & 137,22 \\
\hline Minerais & & 974,9 & 1.012 & 985,3 & 1.092 & 1.666, & 2.289 & 2.969 & $3.493,1$ & 5.673 & $4.781,9$ & 8.379 & $13.374,7$ & 10.330 & 11.881, & & & & \\
\hline & 908,05 & 9 & 95 & 3 & 26 & 65 & 91 & 23 & 8 & 21 & 1 & 15 & 7 & ,47 & 44 & $9.445,03$ & $6.171,86$ & $6.910,93$ & 908,05 \\
\hline & & 186,2 & 161,6 & 130,2 & 288,5 & 354,5 & 459,6 & 971,3 & $1.193,7$ & 1.439 & $1.240,5$ & 1.393, & & 1.327 & $1.125,7$ & & & & \\
\hline & 142,28 & 6 & 6 & 2 & 1 & 3 & 8 & 1 & 9 & 11 & 7 & 81 & $1.558,04$ & 47 & 5 & $1.511,48$ & $1.587,62$ & $1.502,59$ & 142,28 \\
\hline Plástico/borracha & 0,01 & 0,00 & 0,01 & 0,02 & 0,02 & 0,55 & 0,19 & 0,22 & 0,08 & 0,21 & 0,24 & 0,24 & 0,14 & 0,08 & 0,05 & 0,10 & 0,20 & 0,63 & 0,01 \\
\hline Calçados/couro & 0,79 & 1,23 & 2,32 & 6,06 & 4,51 & 3,95 & 3,93 & 26,85 & 38,08 & 15,11 & 21,38 & 36,07 & 41,99 & 55,77 & 105,81 & 100,76 & 71,67 & 48,94 & 0,79 \\
\hline & & 309,0 & 286,2 & 312,6 & 372,5 & 543,4 & 575,2 & 645,2 & & & & & & & & & & & \\
\hline 10 & 277,63 & 4 & 7 & 9 & 5 & 6 & 0 & 5 & 792,86 & 631,31 & 346,10 & 386,68 & 397,65 & 316,91 & 238,62 & 287,64 & 243,58 & 171,58 & 277,63 \\
\hline Panel & & 141,9 & 106,9 & & 130,3 & 143,1 & 155,6 & 180,4 & & & & & & & & & & & \\
\hline & 98,29 & 9 & 6 & 98,19 & 9 & 5 & 3 & 0 & 196,25 & 242,60 & 124,43 & 232,37 & 186,66 & 131,89 & 4,59 & 0,04 & 75,50 & 146,69 & 98,29 \\
\hline Têxtil & 0,47 & 0,41 & 0,43 & 0,45 & 0,18 & 0,31 & 0,16 & 0,09 & 0,03 & 0,12 & 0,13 & 0,09 & 0,02 & 0,04 & 0,03 & 0,03 & 0,05 & 0,05 & 0,47 \\
\hline Min. N.-met/met. & & & & & & & & & & & & & & & & & & & \\
\hline Preciosos & 85,46 & 98,17 & 88,99 & 51,73 & 0,24 & 0,40 & 0,42 & 0,33 & 0,21 & 13,74 & 27,00 & 49,33 & 82,18 & 70,68 & 41,66 & 37,90 & 37,23 & 6,88 & 85,46 \\
\hline Metais comuns & 481,03 & $\begin{array}{c}595,7 \\
3\end{array}$ & $\begin{array}{l}512,1 \\
8\end{array}$ & $\begin{array}{l}573,1 \\
7\end{array}$ & $\begin{array}{c}651,1 \\
1\end{array}$ & $\begin{array}{c}941,6 \\
3\end{array}$ & $\begin{array}{l}1.128 \\
30\end{array}$ & $\begin{array}{l}1.631 \\
38\end{array}$ & $\begin{array}{c}1.698,8 \\
0\end{array}$ & $\begin{array}{l}2.002 \\
98\end{array}$ & $\begin{array}{c}1.066,6 \\
9\end{array}$ & $\begin{array}{c}1.282 \\
27\end{array}$ & $1.612,21$ & $\begin{array}{c}1.297 \\
01\end{array}$ & 894,89 & $1.154,80$ & 864,83 & 664,81 & 481,03 \\
\hline $\begin{array}{c}\text { Máquinas/equipa } \\
\text { mentos } \\
\text { Material }\end{array}$ & 0,70 & 0,21 & 1,17 & 0,05 & 0,11 & 0,20 & 0,87 & 0,20 & 0,06 & 0,31 & 1,13 & 3,37 & 0,06 & 0,84 & 0,61 & 0,22 & 0,96 & 3,91 & 0,70 \\
\hline $\begin{array}{c}\text { transporte } \\
\text { Ótica/instrument }\end{array}$ & 0,00 & 1,18 & 0,00 & 0,05 & 0,03 & 0,26 & 0,78 & 1,23 & 13,32 & 0,25 & 0,01 & 31,52 & 0,00 & 0,00 & 11,21 & 27,21 & 0,48 & 0,70 & 0,00 \\
\hline os & 0,00 & 0,00 & 0,01 & 0,01 & 0,01 & 0,01 & 0,01 & 0,00 & 0,08 & 0,45 & 0,00 & 0,00 & 0,01 & 0,03 & 0,00 & 0,02 & 0,02 & 0,04 & 0,00 \\
\hline Outros & 3,65 & 4,34 & 3,61 & 3,88 & 4,91 & 7,60 & 7,78 & 6,84 & 7,21 & 7,02 & 4,51 & 3,20 & 2,96 & 2,85 & 2,50 & 2,32 & 1,64 & 1,95 & 3,65 \\
\hline Total & $2.135,59$ & $\begin{array}{c}2.440 \\
80 \\
\end{array}$ & $\begin{array}{c}2.288 \\
37 \\
\end{array}$ & $\begin{array}{c}2.266 \\
53 \\
\end{array}$ & $\begin{array}{c}2.677 \\
33 \\
\end{array}$ & $\begin{array}{c}3.804 \\
72 \\
\end{array}$ & $\begin{array}{c}4.806 \\
92\end{array}$ & $\begin{array}{c}6.703 \\
61 \\
\end{array}$ & $\begin{array}{c}7.919,7 \\
1 \\
\end{array}$ & $\begin{array}{c}10.674 \\
, 69 \\
\end{array}$ & $\begin{array}{c}8.338,0 \\
2 \\
\end{array}$ & $\begin{array}{c}12.828 \\
, 53 \\
\end{array}$ & $\begin{array}{c}18.300,4 \\
8 \\
\end{array}$ & $\begin{array}{c}14.750 \\
, 70 \\
\end{array}$ & $\begin{array}{c}15.813 \\
35\end{array}$ & $14.205,24$ & $\begin{array}{c}10.247,9 \\
2\end{array}$ & $\begin{array}{c}10.491,1 \\
8\end{array}$ & $2.135,59$ \\
\hline
\end{tabular}

Fonte: Elaboração própria a partir dos dados MDIC/SECEX (2017b). 


\section{METODOLOGIA}

Na seção da metodologia, identificam-se os quatro indicadores utilizados para o desenvolvimento deste estudo: Vantagem Comparativa Revelada Simétrica (IVCRS), de Comércio Intraindústria (CII), de Concentração Setorial das Exportações (ICS) e Taxa de Cobertura das Importações (TC), a partir de dados da Secretaria de Comércio Exterior - SECEX, os quais objetivam demonstrar os setores do Pará com vantagens comparativas no comércio exterior, ou seja, os setores mais especializados no comércio internacional do estado do Pará.

$\mathrm{O}$ primeiro deles consiste no indicador de Vantagem Comparativa Revelada Simétrica (IVCRS), formalmente definido pela Expressão (1). De acordo com Hidalgo (1998), este indicador revela a relação entre participação de mercado do setor e a participação da região (estado) no total das exportações do país, fornecendo uma medida da estrutura relativa das exportações de uma região (estado). Os resultados do índice variam entre 1 e -1 . Se os resultados estiverem no intervalo de -1 a 0 , não se constata vantagem comparativa, ou seja, a região possui desvantagem na exportação do determinado produto. Caso os valores estejam entre 0 e 1 , indica que a região possui vantagem comparativa em exportar o produto (OLIVEIRA; SCHLINDWEIN, 2015).

$$
\operatorname{IVCRS}_{i k}=\frac{\mathrm{x}_{i j} / \mathrm{x}_{i z}}{\mathrm{x}_{j} / \mathrm{x}_{z}}-1 / \frac{\mathrm{x}_{i j} / \mathrm{x}_{i z}}{\mathrm{x}_{j} / \mathrm{x}_{z}}+1
$$

Em que:

$\mathrm{X}_{i j}$ representa valor das exportações do setor i pelo Estado j (PA);
$\mathrm{X}_{i z}$ representa o valor das exportações do setor i da zona de referência z (Brasil);

$\mathrm{Xj}$ representa valor total das exportações do estado $\mathrm{j}$ (PA); e,

$\mathrm{X}_{\mathrm{z}}$ representa valor total das exportações da zona de referência z (Brasil).

Ainda, conforme Hidalgo (1998), quando uma região exporta um grande volume de um determinado produto em relação ao que é exportado pelo país desse mesmo produto, ela possui vantagem comparativa na produção desse bem. Além disso, em um ambiente cada vez mais globalizado e integrado, o fluxo comercial é caracterizado por um crescente comércio intraindústria. A expansão do comércio nos processos de integração econômica, em geral, acontece através desse tipo de comércio. Assim, o conhecimento desse comércio é importante na formulação de estratégias de inserção internacional para uma economia (HIDALGO; DA MATA, 2004).

O segundo é o Índice de Comércio Intraindústria (CII), o qual visa caracterizar o comércio do estado do Pará. Este índice consiste na utilização da exportação e importação simultânea de produtos do mesmo setor. Com o avanço e difusão dos processos tecnológicos entre os países, muda-se a configuração do comércio internacional e o peso das vantagens comparativas (abundância de recursos). Apresenta-se como destaque o crescimento do comércio interindustrial. Conforme Appleyard, Field Jr. e Cobb (2010), diferentemente do comércio interindustrial, o comércio intraindústria é explicado pelas economias de escala e pela diferenciação do produto. 
O indicador setorial do comércio intraindustrial (CII) foi desenvolvido por Grubel e Lloyd (1975), e pode ser apresentado conforme a Equação 2:

$$
C I I=1-\frac{\sum_{i}\left|X_{i}-M_{i}\right|}{\sum_{i}\left(X_{i}+M_{i}\right)}
$$

Em que:

$\mathrm{X}_{\mathrm{i}}$ representa as exportações do produto $\mathrm{i}$

$\mathrm{M}_{\mathrm{i}}$ representa as importações do produto i.

Quando o indicador CII se aproximar de zero, pode-se concluir que há comércio interindustrial, neste caso, o comércio é explicado pelas vantagens comparativas, ou seja, observa-se a presença de comércio entre produtos de diferentes setores do Pará com os países parceiros. Esse evento pode ser observado ao constatar ocorrência de apenas importação ou apenas exportação do setor i (ou produto i). Por outro lado, quando CII for maior que 0,5 (CII>0,5), o comércio é caracterizado como sendo intraindustrial.

Assim, o padrão de comércio intraindustrial reflete uma pauta exportadora que, por sua vez, sucede uma estrutura produtiva dinamizada em progresso tecnológico e em economias de escala (ampliação de mercados). Todavia, a configuração interindustrial reflete o ordenamento entre os setores produtivos, baseado no uso da dotação de fatores e sob concorrência perfeita. Esse arranjo explicativo das trocas comerciais pode indicar se determinado participante do comércio internacional alcançou ganhos de competitividade. Ressalta-se que, em meio à profusão de conceitos que foram dados a esse termo, entende-se, neste artigo, diante dos alcances e das limitações dos índices utilizados, que alcançar competitividade internacional significa atingir os maiores níveis de vantagem comparativa revelada e o padrão de inserção intraindustrial (FRANCK et al., 2016).

O terceiro indicador é o Índice de Concentração Setorial das Exportações (ICS), também conhecido como coeficiente GiniHirchman, o qual quantifica a concentração das exportações de cada setor exportador i realizados pelo estado j (Pará). O ICS é representado através da Equação 3:

$$
I C S_{i j}=\sqrt{\sum_{i}\left(\frac{X_{i j}}{X_{j}}\right)^{2}}
$$

Em que:

$\mathrm{X}_{\mathrm{ij}}$ representa as exportações do setor $\mathrm{i}$ pelo estado $\mathrm{j}$ (PA); e,

$\mathrm{X}_{\mathrm{j}}$ representa as exportações totais do estado j (PA).

Este índice varia entre 0 (zero) e 1 (um) e, quanto mais próximo de 1 (um), mais concentradas serão as exportações do Estado em poucos produtos; caso contrário, ou seja, quanto mais próximo de zero, mais diversificada será a pauta de exportação do estado (XAVIER; VIANA, 2005).

O quarto indicador é a taxa de cobertura das importações (TC), o qual indica quantas vezes o volume das exportações do setor i está cobrindo seu volume de importação. O índice é obtido através da seguinte Equação 4: 


$$
T C_{i j}=\frac{X_{i j} / M_{i j}}{X_{i} / M_{i}}
$$

Em que:

$\mathrm{Xij}$ representa as exportações do setor i do Estado j (PA);

$\mathrm{M}_{\mathrm{ij}}$ representa as importações do setor i do Estado j (PA);

$\mathrm{X}_{\mathrm{i}}$ representa as exportações do produto $\mathrm{i}$; e,

$\mathrm{M}_{\mathrm{i}}$ representa as importações do produto i.

Se a Taxa de Cobertura (TC) for maior que a unidade, as exportações são superiores às importações do produto i do estado ou região $\mathrm{j}$, indicando que o produto possui vantagem comparativa no comércio e contribui para aumentar a balança comercial do país. Já se o indicador for menor que a unidade, considera-se que há desvantagem comparativa no comércio internacional desse produto e que esse não contribui para a geração de divisas para o país (SOARES; SILVA, 2013).

Para alcançar o objetivo de explanar o padrão comercial da Pará, no período 1999 a 2016, e apresentar os setores com maior produtividade do estado, ou seja, aqueles que apresentam maior especialização e competitividade,foram utilizados indicadores baseados nos fluxos comerciais. O banco de dados para o cálculo destes indicadores encontra-se na Secretaria do Comércio Exterior (SECEX) do Ministério do Desenvolvimento, Indústria e Comércio do Brasil (MDIC, 2017b), acessível através do Sistema de Análise de Informações do Comércio Exterior (Aliceweb2) ${ }^{1}$.

Os dados relativos às importações e às exportações desagregadas por setores seguem o padrão da literatura empírica da área, como apresentam Feistel (2002) e Maia (2005). Tais autores estabelecem capítulos, divididos em setores produtivos, e, deste modo, cada capítulo corresponde a um agrupamento de produtos. Assim, obtêm-se os valores das importações e exportações, agregando-os no padrão já utilizado por tais autores.

\section{ANÁLISE E DISCUSSÃO DOS RESULTADOS}

4.1 Índice de Vantagem Comparativa Revelada Simétrica - IVCRS

A Tabela 3 apresenta a evolução do Índice de Vantagens Comparativas Reveladas Simétricas do Pará de 1999 a 2016. Dos 14 setores analisados, em três o estado do Pará apresentou vantagens comparativas (IVCRS $>0$ ) em todos os anos da série histórica. Ou seja, esses setores apresentaram especialização permanente no que se refere à competitividade e inserção paraense no mercado internacional. Tais setores foram os seguintes, em ordem decrescente de seus valores médios de IVCRS: minerais (média de IVCRS de 0,54), madeira (média de IVCRS de 0,53) e químicos (média de IVCRS de 0,32). Ainda, vale ressaltar que o setor de metais comuns apresentou vantagens comparativas (IVCRS>0) em 16 dos 18 anos abrangidos pela pesquisa e obteve média do indicador no valor de 0,23 .

1 O Sistema Aliceweb2 está disponível no site http://aliceweb2.mdic.gov.br (ALICEWEB, 2017). 
Tabela 3 - Índice de Vantagem Comparativa Revelada Simétrica para o Pará

\begin{tabular}{|c|c|c|c|c|c|c|c|c|c|c|c|c|c|c|c|c|c|c|}
\hline Grupos de Produtos\Ano & 1999 & 2000 & 2001 & 2002 & 2003 & 2004 & 2005 & 2006 & 2007 & 2008 & 2009 & 2010 & 2011 & 2012 & 2013 & 2014 & 2015 & 2016 \\
\hline Alimentos/fumo/bebidas & $-0,64$ & $-0,64$ & $-0,71$ & $-0,72$ & $-0,71$ & $-0,77$ & $-0,75$ & $-0,74$ & $-0,64$ & $-0,66$ & $-0,61$ & $-0,59$ & $-0,70$ & $-0,61$ & $-0,58$ & $-0,52$ & $-0,54$ & $-0,59$ \\
\hline Minerais & 0,70 & 0,66 & 0,64 & 0,60 & 0,58 & 0,61 & 0,56 & 0,48 & 0,45 & 0,46 & 0,50 & 0,43 & 0,44 & 0,47 & 0,54 & 0,49 & 0,57 & 0,62 \\
\hline Químicos & 0,06 & 0,14 & 0,18 & 0,06 & 0,36 & 0,33 & 0,34 & 0,50 & 0,50 & 0,47 & 0,47 & 0,35 & 0,27 & 0,30 & 0,20 & 0,34 & 0,49 & 0,48 \\
\hline Plástico/borracha & $-1,00$ & $-1,00$ & $-1,00$ & $-1,00$ & $-1,00$ & $-0,99$ & $-1,00$ & $-1,00$ & $-1,00$ & $-1,00$ & $-1,00$ & $-1,00$ & $-1,00$ & $-1,00$ & $-1,00$ & $-1,00$ & $-1,00$ & $-1,00$ \\
\hline Calçados/couro & $-0,98$ & $-0,98$ & $-0,96$ & $-0,88$ & $-0,92$ & $-0,94$ & $-0,95$ & $-0,76$ & $-0,71$ & $-0,87$ & $-0,76$ & & & & & & $-0,45$ & $-0,59$ \\
\hline Madeira & 0,63 & 0,64 & 0,65 & 0,65 & 0,66 & 0,63 & 0,64 & 0,61 & 0,65 & 0,61 & 0,58 & 0,51 & 0,48 & 0,46 & 0,28 & 0,33 & 0,33 & 0,12 \\
\hline Papel & 0,00 & 0,10 & 0,09 & 0,10 & 0,10 & 0,09 & 0,04 & $-0,06$ & $-0,10$ & $-0,15$ & $-0,38$ & $-0,31$ & $-0,48$ & $-0,52$ & $-0,98$ & $-1,00$ & $-0,69$ & $-0,49$ \\
\hline Têxtil & $-0,98$ & $-0,99$ & $-0,98$ & $-0,98$ & $-0,99$ & $-0,99$ & $-1,00$ & $-1,00$ & $-1,00$ & $-1,00$ & $-1,00$ & $-1,00$ & & $-1,00$ & $-1,00$ & $-1,00$ & $-1,00$ & $-1,00$ \\
\hline N.-met/met. & 0,21 & 0,23 & 0,26 & $-0,05$ & $-0,99$ & $-0,99$ & $-0,99$ & $-1,00$ & & $-0,87$ & $-0,73$ & $-0,68$ & $-0,61$ & $-0,63$ & $-0,78$ & $-0,78$ & $-0,75$ & $-0,96$ \\
\hline Metais comuns & 0,33 & 0,36 & 0,41 & 0,42 & 0,39 & 0,37 & 0,35 & 0,36 & 0,33 & 0,28 & 0,22 & 0,16 & 0,08 & 0,10 & $-0,05$ & 0,05 & 0,02 & $-0,07$ \\
\hline Máquinas/equipamentos & $-0,99$ & $-1,00$ & $-0,99$ & $-1,00$ & $-1,00$ & $-1,00$ & $-1,00$ & $-1,00$ & $-1,00$ & $-1,00$ & $-1,00$ & $-0,99$ & $-1,00$ & $-1,00$ & $-1,00$ & $-1,00$ & $-1,00$ & $-0,99$ \\
\hline Material transporte & $-1,00$ & $-0,99$ & $-1,00$ & $-1,00$ & $-1,00$ & $-1,00$ & $-1,00$ & $-1,00$ & $-0,97$ & $-1,00$ & $-1,00$ & $-0,95$ & $-1,00$ & $-1,00$ & $-0,99$ & $-0,95$ & $-1,00$ & $-1,00$ \\
\hline Ótica/instrumentos & $-1,00$ & $-1,00$ & $-1,00$ & $-1,00$ & $-1,00$ & $-1,00$ & $-1,00$ & $-1,00$ & $-1,00$ & $-0,98$ & $-1,00$ & $-1,00$ & $-1,00$ & $-1,00$ & $-1,00$ & $-1,00$ & $-1,00$ & $-1,00$ \\
\hline Outros & $-0,75$ & $-0,76$ & $-0,77$ & $-0,79$ & $-0,75$ & $-0,74$ & $-0,76$ & $-0,82$ & $-0,83$ & $-0,85$ & $-0,89$ & $-0,93$ & $-0,95$ & $-0,95$ & $-0,95$ & $-0,95$ & $-0,96$ & $-0,96$ \\
\hline
\end{tabular}

Fonte: Elaboração própria a partir dos dados MDIC/SECEX (2017b). 
O setor de minerais foi o que apresentou o maior valor médio do IVCRS. De acordo com o Instituto Brasileiro de Mineração (IBRAM, 2013), os minerais são um bem com importante participação na pauta exportadora do estado. Assim, de acordo com o IBRAN, as exportações de bens minerais representaram, por exemplo, 77,5\% do total exportado no Pará em 2012. Ainda tomando como base o ano de 2012, o IBRAM afirma que o estado respondeu por $59,4 \%$ das exportações de cobre e $28,4 \%$ do minério de ferro no Brasil. Já em 2013, o estado respondeu por $72 \%$ das exportações de cobre e $29,3 \%$ do minério de ferro no Brasil, aumentando sua participação nas exportações brasileiras destes minerais. A Secretaria de Geologia, Mineração e Transformação Mineral (SGM) do Ministério de Minas e Energia (2017) reitera a importância do minério de ferro para a economia do estado e aponta que, dentro da sua pauta exportadora, a volta do crescimento da produção de minério de ferro no Pará, entre os anos de 2015 e 2016, ajudou a impulsionar o setor mineral brasileiro, que registrou superávit comercial.

Quanto ao comportamento do IVCRS do setor de madeira do estado do Pará, pode-se aliar este comportamento àquilo apontado por Simões, Silva e Silva e Silva (2015). Os autores afirmam que, no estado do Pará, mesmo com os produtos madeireiros perdendo espaço (por ser um setor que induziu aos grandes desmatamentos), o horizonte de possibilidades aponta para um promissor futuro da atividade, dada a reorganização promovida pelo poder público nos últimos anos e levando-se em consideração que ainda são grandes os segmentos do mercado que utilizam a madeira como matéria-prima. Ainda de acordo com os dados dos autores, as exportações de produtos madeireiros no Pará atingiram em 2003 14\% do valor da pauta de exportação do estado, quando em 2011 essa participação era de pouco mais de $2 \%$. Apesar da decepcionante fatia até agora conquistada pelo setor madeireiro no último ano da análise dos autores, segundo os mesmos, a tendência é de estabilidade e progressivo crescimento das exportações nos próximos anos.

Quanto às exportações do setor de químicos, Lobão, Corrêa e Schneider (2017) destacam que, somadas as exportações do Pará com os outros estados que compõem a Região Norte do Brasil, as exportações de químicos aparecem em segundo lugar devido às exportações de produtos químicos e inorgânicos e compostos inorgânicos ou orgânicos. De acordo com os autores, os químicos, dentro da Região Norte como um todo, responderam por $8,75 \%$ do total das exportações, em 2014, mas, em 2015, houve um relativo crescimento, elevando sua participação para $12,22 \%$ do total exportado pela região.

Quanto ao setor de metais comuns, podese destacar que, de acordo com o MDIC (2017b), os dois subsetores do setor de metais comuns que registraram a maior participação foram os de ferro fundido, ferro e aço (feitos a partir de minério de ferro) e os de alumínio e suas obras (que é obtido através do processamento da bauxita). Para o IBRAM (2012), enquanto a cidade paraense de Paragominas merece destaque pelo comércio de alumínio, a cidade de Carajás possui comércio de ferro, bem como outros grupos de metais. A transformação de minerais em metais comuns faz parte da indústria de transformação tradicional, e, 
além de ser vista no Pará, é percebida em outras regiões do país.

Diante destas análises, é possível compreender, sob a ótica das vantagens comparativas, que o Pará possui poucos setores que apresentam vantagens comparativas, ou seja, pauta produtiva com pouca diversificação. Isso pode indicar que o estado possa ser vulnerável às oscilações de variáveis externas (mudança de preços internacionais, crises etc.) e internas (estiagens etc.).
4.2 Índice de comércio intraindústria - CII

Na Tabela 4, apresentam-se os resultados do CII, o qual representa o padrão comercial dentro de um mesmo setor, com os resultados para os 14 setores analisados. Os resultados apontam que não há predominância do CII em nenhum setor, o que indica que a relação do comércio interindústria ainda não é explorada de maneira plena pelo estado do Pará, o que pode ser considerado um dos pontos fracos da estrutura de comércio do mercado paraense. 
Tabela 4 - Índice de comércio intraindústria individual para o Pará

\begin{tabular}{|c|c|c|c|c|c|c|c|c|c|c|c|c|c|c|c|c|c|c|}
\hline Grupos de Produtos\Ano & 1999 & 2000 & 2001 & 2002 & 2003 & 2004 & 2005 & 2006 & 2007 & 2008 & 2009 & 2010 & 2011 & 2012 & 2013 & 2014 & 2015 & 2016 \\
\hline Alimentos/fumo/bebidas & 0,29 & 0,27 & 0,35 & 0,37 & 0,37 & 0,32 & 0,17 & 0,14 & 0,19 & 0,16 & 0,10 & 0,10 & 0,14 & 0,13 & 0,14 & 0,09 & 0,11 & 0,12 \\
\hline Minerais & 0,13 & 0,18 & 0,10 & 0,10 & 0,08 & 0,06 & 0,05 & 0,04 & 0,05 & 0,07 & 0,06 & 0,05 & 0,04 & 0,04 & 0,03 & 0,03 & 0,05 & 0,04 \\
\hline Químicos & 0,27 & 0,30 & 0,46 & 0,43 & 0,27 & 0,24 & 0,29 & 0,21 & 0,20 & 0,28 & 0,30 & 0,21 & 0,29 & 0,36 & 0,34 & 0,25 & 0,23 & 0,28 \\
\hline Plástico/borracha & 0,00 & 0,00 & 0,00 & 0,00 & 0,00 & 0,08 & 0,02 & 0,02 & 0,00 & 0,01 & 0,01 & 0,01 & 0,00 & 0,00 & 0,00 & 0,00 & 0,00 & 0,01 \\
\hline Calçados/couro & 0,49 & 0,52 & 0,44 & 0,09 & 0,11 & 0,05 & 0,15 & 0,03 & 0,05 & 0,13 & 0,08 & 0,08 & 0,11 & 0,07 & 0,05 & 0,06 & 0,06 & 0,04 \\
\hline Madeira & 0,00 & 0,00 & 0,00 & 0,00 & 0,00 & 0,00 & 0,00 & 0,00 & 0,00 & 0,00 & 0,00 & 0,00 & 0,00 & 0,00 & 0,00 & 0,00 & 0,00 & 0,00 \\
\hline Papel & 0,05 & 0,03 & 0,05 & 0,06 & 0,04 & 0,03 & 0,03 & 0,05 & 0,04 & 0,04 & 0,08 & 0,07 & 0,10 & 0,15 & 0,64 & 0,01 & 0,16 & 0,07 \\
\hline Têxtil & 0,19 & 0,10 & 0,16 & 0,12 & 0,05 & 0,19 & 0,06 & 0,02 & 0,01 & 0,02 & 0,03 & 0,01 & 0,00 & 0,01 & 0,01 & 0,00 & 0,01 & 0,01 \\
\hline Min. N.-met/met. Preciosos & 0,04 & 0,17 & 0,02 & 0,05 & 0,60 & 0,19 & 0,80 & 0,23 & 0,05 & 1,00 & 0,22 & 0,15 & 0,31 & 0,34 & 0,38 & 0,21 & 0,18 & 0,41 \\
\hline Metais comuns & 0,02 & 0,01 & 0,02 & 0,01 & 0,01 & 0,02 & 0,07 & 0,02 & 0,04 & 0,04 & 0,08 & 0,09 & 0,14 & 0,12 & 0,18 & 0,16 & 0,15 & 0,14 \\
\hline Máquinas/equipamentos & 0,04 & 0,01 & 0,03 & 0,00 & 0,00 & 0,00 & 0,01 & 0,00 & 0,00 & 0,00 & 0,01 & 0,02 & 0,00 & 0,00 & 0,01 & 0,00 & 0,01 & 0,02 \\
\hline Material transporte & 0,00 & 0,16 & 0,00 & 0,01 & 0,00 & 0,02 & 0,03 & 0,02 & 0,59 & 0,01 & 0,00 & 0,25 & 0,00 & 0,00 & 0,29 & 0,55 & 0,01 & 0,12 \\
\hline Ótica/instrumentos & 0,00 & 0,00 & 0,00 & 0,00 & 0,00 & 0,00 & 0,00 & 0,00 & 0,01 & 0,07 & 0,00 & 0,00 & 0,00 & 0,00 & 0,00 & 0,00 & 0,00 & 0,01 \\
\hline Outros & 0,19 & 0,24 & 0,97 & 0,11 & 0,07 & 0,36 & 0,03 & 0,09 & 0,05 & 0,11 & 0,63 & 0,38 & 0,77 & 0,46 & 0,12 & 0,45 & 0,84 & 0,76 \\
\hline
\end{tabular}

Fonte: Elaboração própria a partir dos dados MDIC/SECEX (2017b). 
Quanto à análise dos setores agregados no CII, os resultados também indicaram comércio interindústria para o Pará, variando em torno de 9\% entre 1999 e 2016. Assim, conforme a Tabela
5, em média, o Pará apresenta especialização no setor de minerais, madeira, químicos e metais comuns, os quais possuem vantagens comparativas.

Tabela 5 - Índice de comércio intraindústria - CII agregado para o Pará

\begin{tabular}{cccc}
\hline Ano & CII & Ano & CII \\
\hline 1999 & 0,10 & 2008 & 0,10 \\
2000 & 0,12 & 2009 & 0,10 \\
2001 & 0,11 & 2010 & 0,08 \\
2002 & 0,09 & 2011 & 0,08 \\
2003 & 0,09 & 2012 & 0,09 \\
2004 & 0,07 & 2013 & 0,08 \\
2005 & 0,08 & 2014 & 0,08 \\
2006 & 0,06 & 2015 & 0,09 \\
2007 & 0,08 & 2016 & 0,09 \\
\hline
\end{tabular}

Fonte: Elaboração própria a partir dos dados MDIC/SECEX (2017b).

Em relação à ausência de comércio intraindutrial, conjectura-se que o estado do Pará ainda não teve significativo impacto na integração regional por meio do aproveitamento do comércio intraindustrial.

4.3 Índice de concentração setorial das exportações - ICS

$$
\text { O comércio exterior do Pará é }
$$
historicamente superavitário. As exportações paraenses cresceram acima da média nacional nos últimos anos, contribuindo para que sua participação nas vendas externas do país passasse de $3,8 \%$, em 2002 , para $4,9 \%$, em 2007 , e $6,1 \%$, em 2012. Merece destaque que, nos últimos cinco anos, as exportações do estado foram impulsionadas pelas vendas de minérios, bovinos vivos e carne bovina, e soja, destinadas, em especial, à China, ao Japão, à Alemanha e à Venezuela (BOLETIM REGIONAL DO BANCO CENTRAL DO BRASIL, 2016).

Diante desse contexto, torna-se pertinente verificar o grau de concentração das exportações do estado. A Tabela 6 apresenta o grau de concentração das exportações - ICS do Pará. 
Tabela 6 - Índice de concentração setorial das exportações para o Pará

\begin{tabular}{llll}
\hline Ano & ICS & Ano & ICS \\
\hline 1999 & 0,51 & 2008 & 0,59 \\
2000 & 0,50 & 2009 & 0,61 \\
2001 & 0,52 & 2010 & 0,68 \\
2002 & 0,53 & 2011 & 0,74 \\
2003 & 0,51 & 2012 & 0,72 \\
2004 & 0,53 & 2013 & 0,76 \\
2005 & 0,55 & 2014 & 0,69 \\
2006 & 0,54 & 2015 & 0,64 \\
2007 & 0,53 & 2016 & 0,68 \\
\hline
\end{tabular}

Fonte: Elaboração própria a partir dos dados MDIC/SECEX (2017b).

Como pode ser observado, é possível afirmar que o Pará apresenta uma pauta de exportações concentrada em poucos setores, visto que a média do indicador (ICS=0,60), no período, oscila entre 0,50 e 0,76 . Esse resultado é reflexo das vantagens comparativas do estado de acordo com os resultados alcançados pelo IVCRS, uma vez que apenas $28,57 \%$ dos setores apresentaram vantagem comparativa, bem como o CII indica que $100 \%$ dos setores apresentam comércio baseado em vantagens comparativas, ou seja, interindustrial. De acordo com SECEX (2017), ao longo do período, os setores que mais aumentaram as exportações foram os de minerais, metais comuns, madeira, químicos, alimentos, fumo e bebidas, papel e minerais não metais/metais preciosos. Todavia, os setores que apresentaram menor crescimento foram "outros", calçados/couro, máquinas e equipamentos, têxtil e plástico/borracha. De acordo com a Tabela 2 (a qual contempla a análise horizontal do crescimento das exportações do estado), os setores que tiveram maior crescimento nas exportações foram aqueles cujo IVCRS indica vantagem comparativa, o que corrobora com a tendência de concentração das exportações do estado do Pará, também indicada pelo ICS.

4.4 Taxa de cobertura das importações - TC

Pode-se destacar, em relação aos resultados da Taxa de Cobertura (TC) das importações do estado do Amazonas, que, dos 14 setores, em dois o estado apresentou taxa de cobertura em todos os anos da série: tais setores foram os de madeira e minerais e apresentaram média do indicador respectivamente no valor de 26891784,38 e 3,20. Entretanto, conforme a Tabela 7, outros 3 setores apresentaram taxa de cobertura na maior parte dos anos abrangidos por esta pesquisa e podem ser elencados de forma decrescente, de acordo com suas respectivas médias de indicador: metais comuns, com média de 6,79; papel, com média de 3,16 e setor de calçados e couro, com média de 2,33. 
Tabela 7 - Taxa de cobertura do comércio do Pará - 1999 - 2016

\begin{tabular}{|c|c|c|c|c|c|c|c|c|c|c|c|c|c|c|c|c|c|c|}
\hline Grupos de Produtos\Ano & 1999 & 2000 & 2001 & 2002 & 2003 & 2004 & 2005 & 2006 & 2007 & 2008 & 2009 & 2010 & 2011 & 2012 & 2013 & 2014 & 2015 & 2016 \\
\hline Alimentos/fumo/bebidas & 0,47 & 0,68 & 0,53 & 0,47 & 0,49 & 0,37 & 0,90 & 1,27 & 0,77 & 1,09 & 1,78 & 1,79 & 0,96 & 1,39 & 0,96 & 1,37 & 1,52 & 1,72 \\
\hline Minerais & 1,14 & 1,09 & 2,05 & 2,12 & 2,52 & 2,44 & 3,32 & 4,74 & 3,14 & 2,65 & 3,23 & 3,41 & 3,34 & 4,63 & 4,07 & 4,08 & 3,83 & 5,88 \\
\hline Químicos & 0,52 & 0,61 & 0,38 & 0,40 & 0,69 & 0,52 & 0,49 & 0,82 & 0,71 & 0,58 & 0,54 & 0,75 & 0,44 & 0,43 & 0,34 & 0,48 & 0,69 & 0,64 \\
\hline Plástico/borracha & 0,00 & 0,00 & 0,00 & 0,00 & 0,00 & 0,00 & 0,00 & 0,00 & 0,00 & 0,00 & 0,00 & 0,00 & 0,00 & 0,00 & 0,00 & 0,00 & 0,00 & 0,00 \\
\hline Calçados/couro & 0,25 & 0,30 & 0,40 & 2,27 & 1,91 & 2,52 & 1,03 & 7,39 & 3,28 & 1,39 & 2,32 & 2,07 & 1,27 & 2,66 & 3,02 & 2,07 & 3,11 & 4,65 \\
\hline Madeira & $\begin{array}{c}171,1 \\
2\end{array}$ & $\begin{array}{c}86,4 \\
0\end{array}$ & $\begin{array}{c}14275,2 \\
1\end{array}$ & $\begin{array}{c}680,7 \\
1\end{array}$ & $\begin{array}{l}5610,6 \\
9\end{array}$ & $\begin{array}{l}2735,1 \\
0\end{array}$ & $\begin{array}{c}483916154,2 \\
7\end{array}$ & $\begin{array}{c}3987,3 \\
0\end{array}$ & $\begin{array}{c}2021,1 \\
4\end{array}$ & $\begin{array}{c}159,2 \\
5\end{array}$ & $\begin{array}{c}102410,8 \\
2\end{array}$ & $\begin{array}{c}1075,1 \\
4\end{array}$ & $\begin{array}{c}1727,4 \\
6\end{array}$ & $\begin{array}{c}97,5 \\
9\end{array}$ & $\begin{array}{c}52,6 \\
2\end{array}$ & $\begin{array}{c}237,9 \\
0\end{array}$ & $\begin{array}{c}112,8 \\
9\end{array}$ & $\begin{array}{c}523,2 \\
5\end{array}$ \\
\hline $\begin{array}{c}\text { Têxtil } \\
\text { Min. N.-met/met. }\end{array}$ & 0,01 & 0,01 & 0,01 & 0,01 & 0,00 & 0,01 & 0,00 & 0,00 & 0,00 & 0,00 & 0,00 & 0,00 & 0,00 & 0,00 & 0,00 & 0,00 & 0,00 & 0,00 \\
\hline Preciosos & 4,47 & $\begin{array}{l}1,17 \\
22,0\end{array}$ & 10,68 & 3,84 & 0,05 & 0,01 & 0,06 & 0,01 & 0,00 & 0,09 & 0,77 & 1,14 & 0,39 & 0,46 & 0,29 & 0,57 & 0,96 & 0,40 \\
\hline Metais comuns & 8,92 & 1 & 10,34 & 21,60 & 22,03 & 6,96 & 2,44 & 8,55 & 4,35 & 4,35 & 2,42 & 1,83 & 1,00 & 1,49 & 0,71 & 0,79 & 1,17 & 1,37 \\
\hline Máquinas/equipamentos & 0,00 & 0,00 & 0,00 & 0,00 & 0,00 & 0,00 & 0,00 & 0,00 & 0,00 & 0,00 & 0,00 & 0,00 & 0,00 & 0,00 & 0,00 & 0,00 & 0,00 & 0,00 \\
\hline Material transporte & 0,00 & 0,01 & 0,00 & 0,00 & 0,00 & 0,00 & 0,00 & 0,00 & 0,03 & 0,00 & 0,00 & 0,01 & 0,00 & 0,00 & 0,01 & 0,03 & 0,00 & 0,01 \\
\hline Outros & 0,78 & 0,80 & 0,12 & 1,83 & 3,17 & 0,32 & 5,91 & 2,10 & 3,21 & 1,56 & 0,04 & 0,38 & 0,12 & 0,03 & 0,00 & 0,02 & 0,07 & 0,17 \\
\hline
\end{tabular}

Fonte: Elaboração própria a partir dos dados MDIC/SECEX (2017b). 
A taxa de cobertura para o setor de madeira apresenta a maior média em relação ao período da pesquisa. De acordo com Figueiras et al. (2008), o Pará é o terceiro estado no ranking das exportações e concentra $75 \%$ da madeira extraída de floresta nativa no país. Para Silva (2013), a importância das exportações de madeira do estado tem relação com segmento de madeira sólida em tora, que é de fundamental importância para a economia paraense, visto que exerce papel importante junto às exportações do setor, viabilizando o fornecimento de matéria-prima para as indústrias de móveis locais. Deste modo, participa de toda a cadeia produtiva da madeira, impulsionando o aumento na demanda de matériaprima e o de produtos manufaturados, alavancando as economias locais e regional. Ainda de acordo com Silva (2013), o Pará, historicamente, figurou como grande produtor e exportador de madeira para outros estados e para o mercado internacional.

Quanto ao setor de minerais, o Departamento Nacional de Produção Mineral (DNPM, 2016) destaca que as exportações de ferro do estado do Pará bem como o volume das exportações paraenses de bens minerais obtiveram um crescimento de 2015 para 2016, o que registrou maior exportação foi o ferro, com 144.686.031 milhões de toneladas, crescendo $16,3 \%$ quando comparado a 2015, quando foram exportados 124.363.055 milhões de toneladas. O valor da comercialização das exportações minerais paraenses passou de R\$ 20.062.831.227,6 bilhões para R\$ 21.911.690.681,9 bilhões, aumentando 9,2\% entre 2015 e 2016, e as exportações de ferro sozinhas acumularam o valor de R\$ 14.408.621.905,8 bilhões.

Por sua vez, em relação ao setor de metais comuns, de acordo com o Governo do Pará (2011), enquanto as exportações da indústria extrativa mineral se concentram em minérios de ferro (aproximadamente $85 \%$ do total), as exportações da indústria de transformação mineral, que englobam as exportações do setor de metais comuns, concentram-se em alumina calcinada (aproximadamente $46 \%$ do total) e alumínio (aproximadamente $29 \%$ do total). O alumínio provém da alumina, que, por sua vez, por meio de um refino, vem da mineração de bauxita.

Quanto à taxa de cobertura do setor de papel, que engloba tanto papel quanto celulose, a Câmara de Comércio e Indústria Brasileira (CCIBRA, 2017) destaca que, dentro da pauta exportadora do estado do Pará, a celulose é o $7^{\circ}$ setor com maior volume de exportações, e corresponde a $4,1 \%$ do total exportado pelo estado.

Por último, em relação à taxa de cobertura das exportações do setor de calçados e couro, os resultados podem ser relacionados com o desenvolvimento da pecuária no estado do Pará. Teixeira e Hespanhol (2014) afirmam que o efetivo do rebanho bovino do país apresentou incremento de 43,6\%, entre 1990 e 2012, com grandes diferenças de desempenho entre os Estados da federação. Nesse período, os autores destacam que ocorreu grande expansão dos rebanhos de alguns estados, e o Pará foi um destes estados que apresentou grande aumento do rebanho bovino, base para a produção de couro animal. 


\section{CONCLUSÕES}

Este estudo permitiu aprofundar as observações em relação ao padrão do comércio exterior dos diversos setores do estado do Pará. A visão integral dos resultados apresentados neste artigo permite destacar as peculiaridades estaduais da competitividade do Pará no comércio exterior, mostrando que existem quatro grupos competitivos no mercado internacional: minerais, madeira, químicos e metais comuns. Os resultados do IVCRS clarificam que é possível afirmar que o Pará apresenta uma pauta exportadora pouco diversificada, o que ocasiona sua maior dependência econômica em relação ao mercado externo. Quanto ao índice de Comércio Intraindústria (CII), os resultados alcançados apontam que tal forma de comércio não é plenamente explorada por nenhum setor do estado do Pará.

Deste modo, o Índice de Vantagens Comparativas Reveladas Simétricas (IVCRS) e o Índice de Comércio Intraindústria (CII) demonstram um padrão de exportação baseado prioritariamente em produtos intensivos em recursos naturais e produtos da indústria de transformação tradicional, os quais são pouco capazes de gerar vantagens comparativas dinâmicas, ou seja, baseados em inovações tecnológicas, como são encontradas nos padrões internacionais de comércio dos países desenvolvidos. Embora o setor de químicos tenha apresentado resultados positivos em relação ao IVCRS, e este seja um setor de média-intensidade tecnológica, os resultados são incipientes, haja vista que este setor corresponde a apenas 7,14\% dos setores da pauta exportadora do estado.
Assim, o comércio paraense obedece a um comportamento predominantemente interindustrial, ou seja, explicado pelas vantagens comparativas.

Quanto ao Índice de Concentração Setorial (ICS), o Pará apresenta uma pauta de exportações concentrada em poucos setores, com média do indicador de 0,60 ao longo do período analisado, refletindo o IVCRS, visto que apenas quatro setores apresentaram vantagens comparativas (os quais correspondem a $28,57 \%$ do total de setores da pauta exportadora) e, além disto, o CII também indica que 100,00\% dos setores apresentam comércio predominantemente baseado em vantagens comparativas, ou seja, interindustrial. Ainda, em relação à Taxa de Cobertura (TC) das importações, ela revela que, ao longo de todo o período, os setores que apresentaram taxas de cobertura foram os de madeira, minerais, calçados e couro papel e metais comuns.

Em relação aos parceiros comerciais, a China se apresenta como principal país importador, cenário diferente do observado em 1999, em que o Japão era o maior comprador de produtos do Pará. Em relação ao padrão setorial das exportações, observa-se que houve poucas mudanças na inserção setorial externa, na qual os produtos básicos tiveram um aumento na sua participação na pauta exportadora do estado enquanto os semimanufaturados sofreram uma redução.

Entre as limitações do trabalho está o fato de os índices utilizados serem estáticos, ou seja, permitem a análise em períodos de tempos específicos, não compreendendo diversas alterações econômicas. Neste sentido, fazem-se 
pertinentes análises com acuidade, utilizando modelos mais robustos, tais como econométricos, bem como de Equilíbrio Geral de Gerações Sobrepostas.

\section{REFERÊNCIAS}

ANÁLISE DAS INFORMAÇÕES DE COMÉRCIO EXTERIOR - ALICEWEB. Consultas. Disponível em: < http://aliceweb.mdic.gov.br/ >. Acesso em: 15 jan. 2017.

APPLEYARD, D.; FIELD JR., A, J.; COBB, S. L. Economia Internacional. 6 ed. Porto Alegre: McGraw Hill, 2010.

BOLETIM REGIONAL DO BANCO CENTRAL DO BRASIL. Economia Paraense: estrutura produtiva e desempenho recente. 2016. Disponível em: < http://www.bcb.gov.br/pec/boletimregional/port/2016/ 04/br201604b1p.pdf >. Acesso em: 14 jan. 2017.

CÂMARA DE COMÉRCIO E INDÚSTRIA BRASILEIRA - CCIBRA. Economia do estado do Pará. 2017. Disponível em: < http://ccibra.com.br/novo/galeria-de-fotos/1-rio-dejaneiro/detail/7-rio-de-janeiro?tmpl=component $>$. Acesso em: 05 ago. 2017.

\section{DEPARTAMENTO NACIONAL DE PRODUÇÃO} MINERAL - DNPM. Informe mineral do estado do Pará. 2016. Disponível em: <

http://www.dnpm.gov.br/dnpm/informes/informe_mine ral_0_2016 >. Acesso em: 25 jul. 2017.

FEISTEL, P. R. Modelo Gravitacional: um teste para economia do Rio Grande do Sul. Revista Economia, Negócios e Finanças, v. 1, n. 1, p. 94-107, jul./dez. 2002 .

FERREIRA, M. D. P.; LÍRIO, V. S.; MENDONÇA, T. G. de. Análise do Perfil e Grau de Incidência de Barreiras Não-Tarifárias sobre as Exportações Brasileiras de Frutas

Selecionadas. Revista de Economia do Nordeste, Fortaleza, v. 41, n. 4, p. 683-698, out./dez. 2010.

FIGUEIRAS, G. C.; SANTANA, A. C. de; HOMMA, A. K. O.; HERREROS, M. M. A. G.; BARROS, P. L. C. de; MENDES, F. A. T. Arranjos produtivos locais no estado do Pará: localização espacial das atividades florestal e de madeira e mobiliário. Revista de

Economia e Agronegócio, v. 6, n. 1, p. 81-104, 2008.

FRANCK A. G. S.; SILVA, M. L. da; SILVA, R. A. da; CORONEL, D. A. Padrão de especialização do comércio internacional do Rio de Janeiro (1999-2015).
Revista Estudo \& Debate em gestão e planejamento, UNIVATES, v. 23, n. 2, p. 160-179, 2016.

GOVERNO DO PARÁ. Plano de Mineração do Estado do Pará: 2014-2030. 2011. Disponível em: < http://sedeme.com.br/portal/download/pem-2030.pdf >. Acesso em: 26 jul. 2017.

GRUBEL, H.; LLOYD, P. Intra-Industry Trade: the theory and the measurement of international trade in differentiated products. London: Macmillan, 1975. HIDALGO, A. B. Especialização e competitividade do Nordeste brasileiro no mercado internacional. Revista Econômica do Nordeste, Fortaleza: BNE, v. 29, p. 491-414, jul./set. 1998.

HIDALGO, A. B.; DA MATA, D. F. P. G. Exportações do Estado de Pernambuco: concentração, mudança na estrutura e perspectivas. Revista Econômica do Nordeste, Fortaleza, v. 35, n. 2, p. 264283, abr./jun. 2004.

INSTITUTO BRASILEIRO DE MINERAÇÃO IBRAM. Informações e análises da economia mineral brasileira. 2012. Disponível em: < http://www.ibram.org.br/sites/1300/1382/00002806.pdf >. Acesso em: 05 ago. 2017.

INSTITUTO BRASILEIRO DE MINERAÇÃO IBRAM. Informações sobre a economia mineral do estado do Pará. 2013. Disponível em: < http://www.ibram.org.br/sites/1300/1382/00003788.pdf >. Acesso em: 05 ago. 2017.

LIMA, J. B.; SILVA, J. M. P. DINÂMICAS ECONÔMICAS E ORDENAMENTOS TERRITORIAIS DOS GRANDES PROJETOS DE MINERAÇÃO NO ESTADO DO PARÁ (2009-2014): O CASO DE PARAGOMINAS. Geosaberes, Fortaleza, v. 6, número especial (3), p. 402-416, 2016.

LOBÃO, M. S. P.; CORRÊA, A. de S.; SCHNEIDER, M. B. Região Norte do Brasil e sua inserção no comércio internacional brasileiro. Interações, v. 18, n. 2, p. 87-102, 2017.

MAIA, S. F. Transformações na estrutura produtiva do estado do Paraná na década de 90: análise por vantagem comparativa. In: MAIA, S. F.; MEDEIROS, N. H. (Org.). Transformações Recentes da Economia Paranaense. Recife: Editora Universitária, v. 1, p. 6588, 2005. 
MINISTÉRIO DO DESENVOLVIMENTO, INDÚSTRIA E COMÉRCIO EXTERIOR. Balança

Comercial. 2017a. Disponível em:

<http://www.mdic.gov.br/comercio-

exterior/estatisticas-de-comercio-exterior/balanca-

comercial-brasileira-unidades-da-federacao>. Acesso

em 08: fev. 2017.

\section{MINISTÉRIO DO DESENVOLVIMENTO,}

INDÚSTRIA E COMÉRCIO EXTERIOR. Séries

Históricas. 2017b Disponível em:

<http://www.mdic.gov.br/comercio-

exterior/estatisticas-de-comercio-exterior/series-

historicas>. Acesso em: 08 fev. 2017.

OLIVEIRA, M. de F.; SCHLINDWEIN, M. M. Índice de vantagem comparativa revelada para o complexo soja da região centro-oeste brasileira. Revista de

Estudos Sociais, v. 17, n. 33, p. 109-131, 2015.

\section{SECRETARIA DE GEOLOGIA, MINERAÇÃO E} TRANSFORMAÇÃO MINERAL - SGM. Produção de minério de ferro cresce no Pará entre 2015 e 2016. 2017. Disponível em: < http://socelnews.blogspot.com.br/2017/01/producaode-minerio-de-ferro-cresce-no.html >. Acesso em: 05 ago. 2017.

SILVA, F. L. da. A dinâmica autoregressiva do mercado de madeira para processamento e seus efeitos no desflorestamento. Observatorio de la Economía Latinoamericana, n. 188, p. 1-18, 2013.

SIMÕES, J. E. M.; SILVA e SILVA, E. da; SILVA, D. C. C. Análise da exportação de madeira do Pará em período recente. Cadernos CEPEC, v. 4, n. 2, p. 1-26, 2015.

SOARES, N. S.; SILVA, M. L. Competitividade brasileira no comércio internacional de produtos extrativos vegetais. Revista Econômica do Nordeste, Fortaleza, v. 44, n. 4, p. 879-893, out./dez. 2013.

TEIXEIRA, J. C.; HESPANHOL, A. N. A trajetória da pecuária bovina brasileira. Caderno Prudentino de Geografia, n. 36, v. 1, p.26-38, jan./jul. 2014.

TOBIAS, M. S. G.; COSTA, R. R. da; BAHIA, P. Q. P. Análise logística de cenários dos fluxos de transportes em áreas do setor mineral na mesorregião sudeste do Pará através da ferramenta SIG. Revista Caribeña de Ciencias Sociales, p. 1-18, dez. 2014.

XAVIER, C. L.; VIANA, F. D. F. Inserção externa e competitividade dos estados da região Nordeste do Brasil no período 1995-2004. Revista Econômica do Nordeste, Fortaleza, v. 36, n. 3, p. 456-469, 2005.

\begin{tabular}{l}
\hline Laís Viera Trevisan \\
Mestranda do Programa de Pós-Graduação em \\
Gestão de Organizações Públicas (PPGOP) da \\
Universidade Federal de Santa Maria (UFSM). \\
Bacharel em Administração, UFSM. Assistente em \\
Administração- UFSM. \\
\hline
\end{tabular}

\section{Giulia Xisto de Oliveira}

Acadêmica do curso de Administração da Universidade Federal de Santa Maria (UFSM).

\footnotetext{
Daniel Arruda Coronel

Professor Adjunto dos Programas de Pós-Graduação Gestão de Organizações Públicas (PPGOP), do de Agronegócios e do de Economia e Desenvolvimento (PPGE\&D) da Universidade Federal de Santa Maria (UFSM) e Diretor da Editora da UFSM.
} 